\title{
Recovery of orthometric heights from ellipsoidal heights using offsets method over Japan
}

\author{
Patroba Achola Odera ${ }^{*}$ and Yoichi Fukuda ${ }^{2}$
}

\begin{abstract}
One of the most important applications of a geoid model is a recovery of orthometric heights from ellipsoidal heights (normally obtained from GNSS). The application of the geoid model for recovering orthometric heights from ellipsoidal heights is normally achieved by fitting the geoid model to a local vertical datum. The fitting procedure is usually accomplished by least squares collocation (LSC), using planar or spherical covariance functions. This procedure warps the gravimetric geoid model onto the local vertical datum, hence the local geoid model derived by this procedure, though convenient for local applications, it is not an equipotential surface. We propose offsets method for practical orthometric height recovery from a geoid model. The proposed procedure is more realistic because it does not constrain the local geoid to be coincident to the local vertical datum. We compare the performance of plannar fitting and offsets methods over Japan using a cross-validation procedure. Results show that offsets method performs better than the normally used planar fitting in the recovery of orthometric heights from ellipsoidal heights using a geoid model. The standard deviations of the differences between established and converted orthometric heights at randomly selected GPS/levelling test points over Japan are \pm 4 and $\pm 3 \mathrm{~cm}$ for planar fitting and offsets methods, respectively. The offsets method is therefore more appropriate for converting ellipsoidal heights to orthometric heights than the planar fitting in the area of study.
\end{abstract}

Keywords: Orthometric height; Ellipsoidal height; Geoid model; Planar fitting; Offsets method; Least squares collocation; Kriging

\section{Background}

One of the challenges to geodesists today is how to determine a consistent and functional vertical component of the geodetic datum. The existing height systems are defined in different ways but basically referred to the local mean sea level. The natural height datum is the geoid, which is part of the integrated geodetic datum. In geodetic positioning, the geoid is normally approximated with a rotational reference ellipsoid (with semi-minor axis perpendicular to the equatorial plane) as a conventional reference surface.

The precise geoid model not only enables us to convert ellipsoidal heights to levelled heights but also plays an important role in combining levelling data with GPS

\footnotetext{
* Correspondence: podera@jkuat.ac.ke

'Department of Geomatic Engineering and Geospatial Information Systems, Jomo Kenyatta University of Agriculture and Technology, 62000-00200,

Nairobi, Kenya

Full list of author information is available at the end of the article
}

measurements to study vertical crustal movements for a longer period of time (Kuroishi et al. 2002). Amos and Featherstone (2009) investigated the use of quasi-geoid in the unification of New Zealand's local vertical datums. A precise geoid model is necessary for the establishment of a rigorous orthometric height system and unification of vertical datums. An accuracy of $\pm 1 \mathrm{~cm}$ for the global geoid model is considered sufficient for these purposes. However, the current high-resolution gravitational model (EGM2008) approximates the global geoid at an accuracy of $\pm 15 \mathrm{~cm}$ (e.g. Pavlis et al. 2012).

Satellite positioning is gaining a lot of applications in Earth sciences today. One of the most extensively used satellite positioning in Earth sciences is the Global Positioning System (GPS). It is fast and efficient in determination of positions based on the World Geodetic System of 1984 (WGS84). It measures heights above WGS84 reference ellipsoid. These heights are called ellipsoidal

\section{实 Springer}


heights $(h)$. However, orthometric heights $(H)$ are the functional heights for mapping, engineering works, navigation and other geophysical applications (Ayhan 1993).

The orthometric heights are normally obtained through spirit levelling, which is a very tedious and expensive process. The application of GNSS for height determination using a precise geoid model is desired. The current application involves warping the gravimetric geoid model to fit onto the local vertical datum. The problem with this method is that the surface realised after fitting is not an equipotential surface hence its physical applications are limited.

This paper describes the procedure of vertical datum establishment and related practical challenges. From the practical challenges, the usual straightforward relationship between the vertical datum (obtained through spirit levelling) and the reference ellipsoid (obtained through GPS levelling) is modified by adding another variable called an offset (distance between the geoid and a local vertical datum). It then compares two methods (planar fitting and offsets) for orthometric height recovery from a regionally defined gravimetric geoid model over Japan. An improved geoid model over Japan (Odera and Fukuda 2014) and rigorous orthometric heights over Japan (Odera and Fukuda 2015) have been used in this study. To avoid unnecessary repetitions of rigorous orthometric heights, they are simply referred to as orthometric heights in the subsequent sections.

\section{Methods}

\section{Establishment of a vertical datum}

Although the global horizontal positioning is currently being achieved through ITRF, a functional vertical datum remains a problem at the local, regional and global levels. The usual way of obtaining heights from appropriate height differences is to begin at the seashore where the geoid, or quasi-geoid, is accessible (Vaníček and Krakiwsky 1982). For practical convenience, the mean sea level is normally assumed to be coincident with the geoid or that the separation between them is negligible. Although this assumption is valid theoretically, it is difficult to achieve in practice. The establishment of the vertical datum is achieved by determining the mean sea level on the seashore. A tide gauge station is set up at the seashore and next to it, a reference benchmark (RBM) is established as shown in Fig. 1.

The difference in height between the RBM and the conventional zero of the tide gauge (CZTG), $\Delta H_{\mathrm{BM}-\mathrm{TG}}$, is precisely determined. Observations at the tide gauge are made over a period of time (preferably 18.6 years, but rarely met in practice) to determine the local mean sea level, $H_{\mathrm{LMSL}}$. The height of the RBM above LMSL is then obtained as $H_{\mathrm{LMSL}}+\Delta H_{\mathrm{BM}-\mathrm{TG}}$. The heights of all other points in the network are subsequently obtained from the height of the RBM by accumulating the height differences along the interconnecting levelling lines (Cannon 1929).

The heights derived in this manner are generally referred to as orthometric heights $(H)$. It should be noted that the position of the instantaneous sea level (ISL) in Fig. 1 is only indicative (the exact position may vary). In this approach, each country defines its own mean sea level, hence the existence of numerous vertical datums in the world today. The assumption that the geoid coincides with the mean sea level ignores the presence of sea surface topography (SST) as shown in Fig. 1. Rizos (1980) observed that the mean value of LMSL observed at the tide gauge stations cannot be considered to coincide with the geoid. Similar studies also confirmed this fact (Rapp and Balasubramania 1992; Pan and Sjöberg 1998).

\section{Planar fitting and offsets methods}

Currently, the local geoid model is assumed to coincide with the local vertical datum in most practical applications. This ignores the existence of the SST and distortions in the local vertical datum (LVD). Distortions in

Fig. 1 Establishment of a local vertical datum 
the local vertical datum are mostly caused by periodic crustal deformations while the inconsistency between the LMSL and geoid (SST) is largely caused by short and long periodic factors, e.g. air pressure, ocean temperature, glacial melt, long periodic tides and polar motion, among other factors. The set-up is shown in Fig. 2. A simplified mathematical model in this assumption, ignoring the small contribution of the total deflection of the vertical $(\theta)$ for practical applications, is normally given as

$$
N=h-H
$$

where $N$ is the gravimetric geoid undulation, $H$ is orthometric height based on the local vertical datum and $h$ is ellipsoidal height at a point $P$, on the topographical surface. Equation (1) shows a perfect scenario which deviates from the practical reality because of the way local vertical datums are established, orthometric height system adopted and related systematic and non-systematic errors.

It should be noted that there is no vertical datum in the world today that is based on a rigorous orthometric height system. This is because of the difficulty in determining rigorous mean gravity along the plumbline between the geoid and a point at the topographical surface. This set-up may work after making a number of assumptions (not necessarily valid), where the local vertical datum is to be maintained and the problem is only how to convert ellipsoidal heights into the local vertical datum. However, it cannot be used in a country where there are many local height datums or systems. It is also not applicable for unification of regional height datums. This is the usual technique used in the conversion of ellipsoidal heights into orthometric heights. Planar or spherical covariance functions are normally used to fit a gravimetric geoid model onto a local vertical datum. The interpolation of geoid undulations is done using least squares collocation (LSC). Development and applications of LSC techniques in geodesy and related fields have been studied by several authors (e.g. Krarup 1969; Moritz 1973; Tscherning 1976; Kearsley 1977; Moritz 1980; Knudsen 1987; Forsberg 1987; Schaffrin 1989).

We propose a solution that treats the local vertical datum as a constant surface at the origin but varying elsewhere due to distortions in the local vertical datum. The local vertical datum may deviate from the "true" local mean sea level depending on how the vertical datum is determined and the height system adopted. The local mean sea level also varies from the local geoid model because of the presence of SST (more specifically, dynamic sea surface topography). A simplified representation of this set-up is given in Fig. 3.

Considering Fig. 3, the relationship between the local vertical datum, local geoid model and reference ellipsoid is expressed as

$$
O_{\mathrm{LVD}}=h-H-N \text {, }
$$

where $O_{\mathrm{LVD}}$ is the offset of the existing LVD with respect to the local geoid, the orthometric height $H$ is obtained from the local levelling network, ellipsoidal height $h$ is obtained from GPS data and the geoid undulation $N$ is obtained from a precise geoid model.

The above procedure is more realistic because it does not constrain the local geoid to be coincident to the local vertical datum. It can be used for the establishment of a geoid consistent vertical datum and regional unification of height datums using a precise regional geoid model. The set-up can also be applied where the local vertical datum is to be maintained and the problem is only how to convert ellipsoidal heights into the local orthometric heights. In this procedure, the geoid undulation

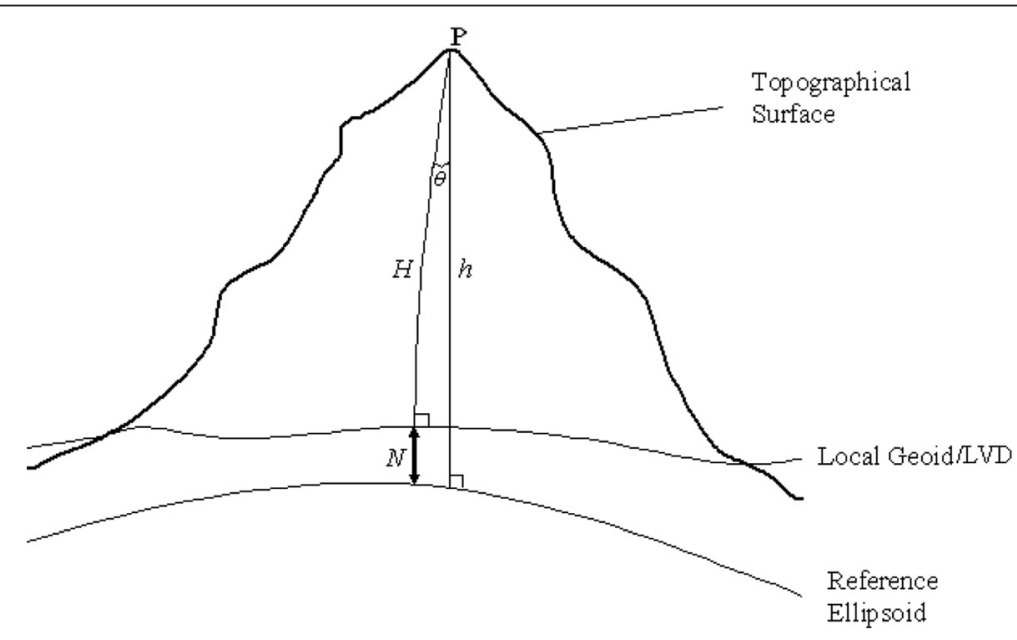

Fig. 2 Local geoid (local vertical datum) and reference ellipsoid 


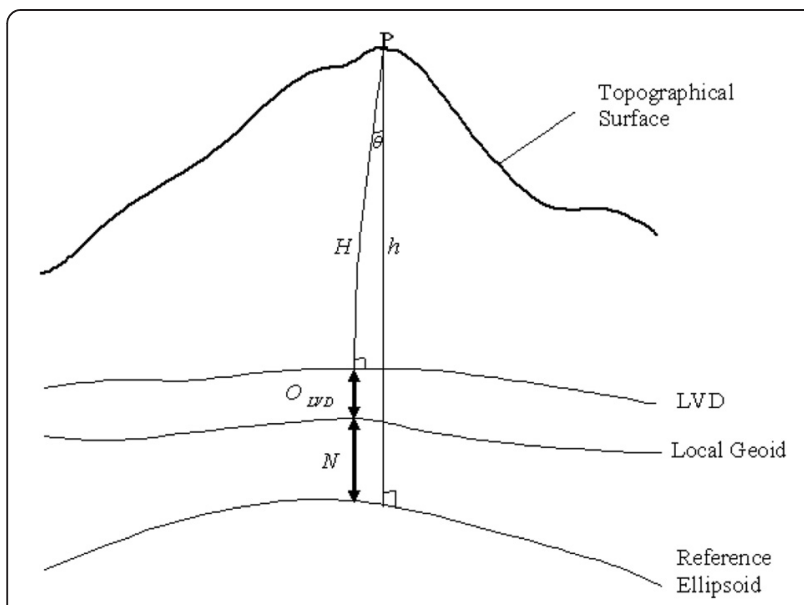

Fig. 3 Local vertical datum, local geoid and reference ellipsoid

and offset are interpolated using Kriging technique (Krige 1951; Schaffrin 2001). This technique is referred to as offsets method in this study. A comparative study of the two techniques (LSC and Kriging) in interpolation of gravity anomalies can be found in Odera et al. (2012). Amos and Featherstone (2009) used a similar model for unification of vertical datums based on a quasi-geoid model in New Zealand. They used an iterative gravimetric quasi-geoid computation procedure which is different from our proposal. A new method used over Japan decomposes differences between GPS/levelling and gravimetric geoid undulations into two components, namely ramp and residual geoid height but applies LSC for fitting (Miyahara et al. 2014).

\section{Results and discussion}

The local vertical datum offsets over Japan are computed by Equation (2) at $816 \mathrm{GPS} /$ levelling points using gravimetric geoid undulations on a $1 \times 1.5$ arc-minute grid (Odera and Fukuda 2014). Figure 4 shows the distribution of GPS/levelling data over Japan. The offsets are then interpolated onto the grids ( 1 by 1.5 arc-minute) using Kriging technique. This means that there is a gravimetric geoid undulation and an offset for every grid point. Spatial distribution of the offsets over the study area is shown in Fig. 5. The converted orthometric height at a point is then obtained as

$$
H=h-N-O_{\mathrm{LVD}},
$$

where the gravimetric geoid undulation $(N)$ and offset $\left(O_{\mathrm{LVD}}\right)$ are interpolated from the neighbouring grids by inverse distance weighting (IDW) for easier application. IDW is a practical approximation that would not need extra painstaking computation at the application level.

To assess the accuracy of this technique, 20 GPS/levelling points, evenly distributed over Japan, are randomly

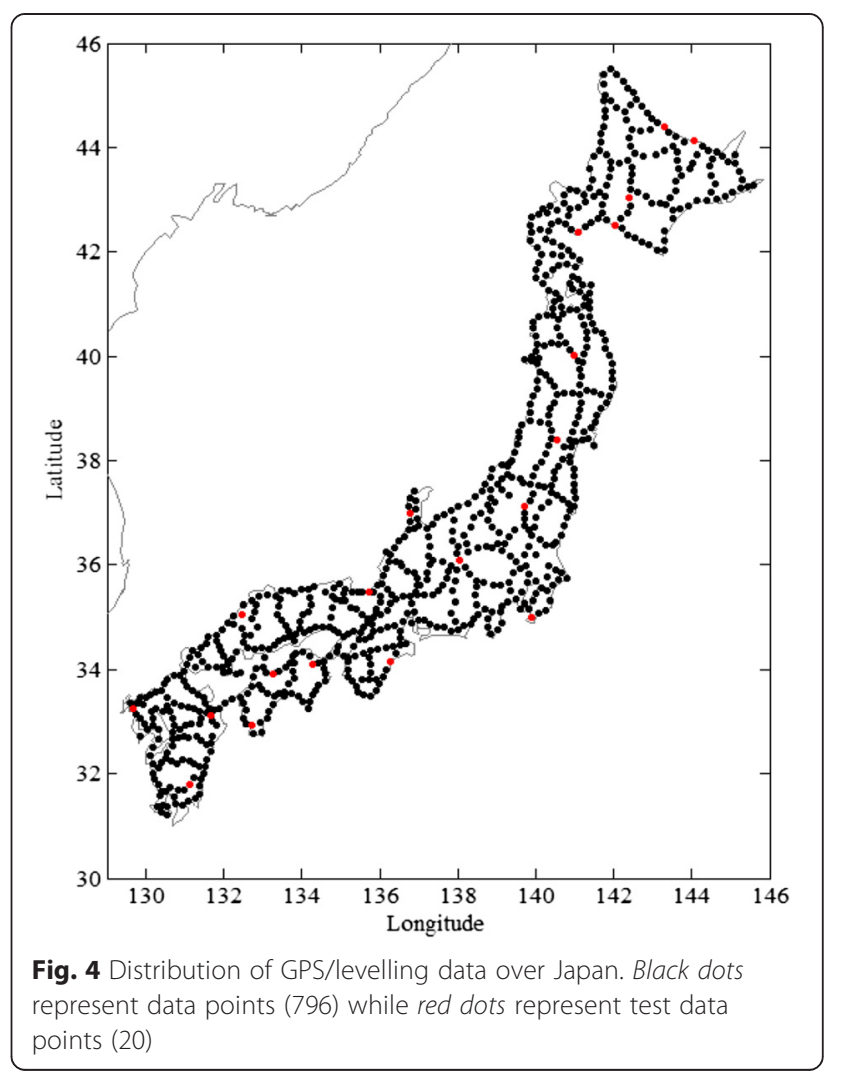

selected (out of 816 points) as test points. The remaining 796 points are used as data points. Figure 4 shows the distribution of data and test points. The test points are excluded in the evaluation of Kriging parameters to facilitate a cross-validation procedure. They are also excluded in the IDW interpolation. The converted orthometric heights (Equation 3) at the test points are compared with the established orthometric heights. The comparison is also carried out using the planar fitting by LSC. Again, the test points are excluded in the evaluation of empirical covariance function in LSC. The statistics of the differences between the established and converted orthometric heights at 20 test points using the planar fitting and offsets methods are given in Table 1. The actual differences between the established and converted orthometric heights at the test points using offsets method are given in Fig. 6.

The standard deviations of the differences between established and converted orthometric heights at the test points using planar fitting and offsets methods are \pm 4.0 and $\pm 3.3 \mathrm{~cm}$, respectively. The offsets method is therefore more appropriate for accurate conversion of ellipsoidal heights to orthometric heights over Japan than the planar fitting. The actual height differences (Fig. 6) show that the orthometric heights of most points (16 out of 20) would be determined within $4 \mathrm{~cm}$. Although offsets method is being applied for the first time over Japan, LSC has been used in the past with similar results as 


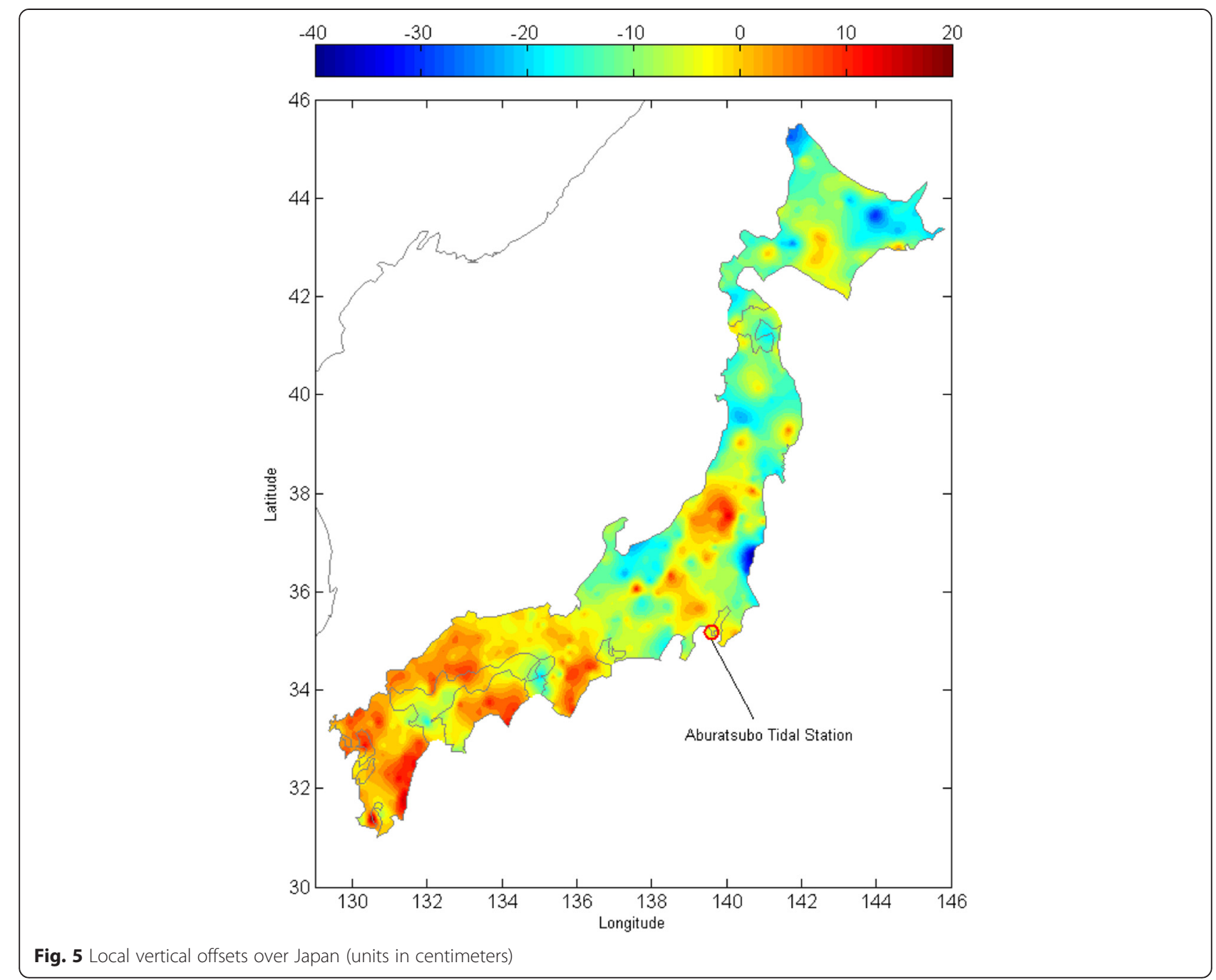

obtained in this study (e.g. Fukuda et al. 1997; Kuroishi et al. 2002; Kuroishi, 2009).

Apart from orthometric height determination from ellipsoidal height, local vertical offsets can be used to study deformations related to a local vertical datum although only approximately. The offsets around Aburatsubo tidal station in Tokyo Bay (origin of levelling network) is nearly $0 \mathrm{~cm}$ (Fig. 5), indicating a near coincidence between the geoid model and the Japanese local vertical datum at the origin. However, two distinct trends are observed with reference to Aburatsubo tidal station. The local vertical datum is generally below the

Table 1 Statistics of the differences between established and converted orthometric heights at 20 test points, using planar fitting and offsets methods (units in centimeters)

\begin{tabular}{lllll}
\hline Method & Min & Max & Mean & SD \\
\hline Planar fitting & -7.75 & 5.34 & -1.19 & 3.99 \\
Offsets & -6.72 & 5.81 & -0.55 & 3.28 \\
\hline
\end{tabular}

gravimetric geoid model towards north while the local vertical datum is generally above the gravimetric geoid model towards south. This interpretation is based on the fact that gravimetric geoid model in the study area is above the reference ellipsoid. The two trends are not uniform indicating the presence of systematic errors (error propagation with distance from the origin) and non-systematic errors. The non-systematic errors may be due to ground movements caused by crustal deformations. Large offsets $(>15$ and $<-25 \mathrm{~cm}$ ) are generally occurring in known tectonically active areas over Japan. Crustal deformations over Japan caused by earthquakes, tsunamis, volcanic eruptions and related forces have led to a number of revisions of geodetic control values due to displacement of physical survey marks (e.g. Doi et al. 2005; Tobita 2009; Hiyama et al. 2011).

The boundary between vertical datum and a precise geoid model cannot be explained purely from this study. The said boundary is a result of various errors associated with geoid determination, local vertical 


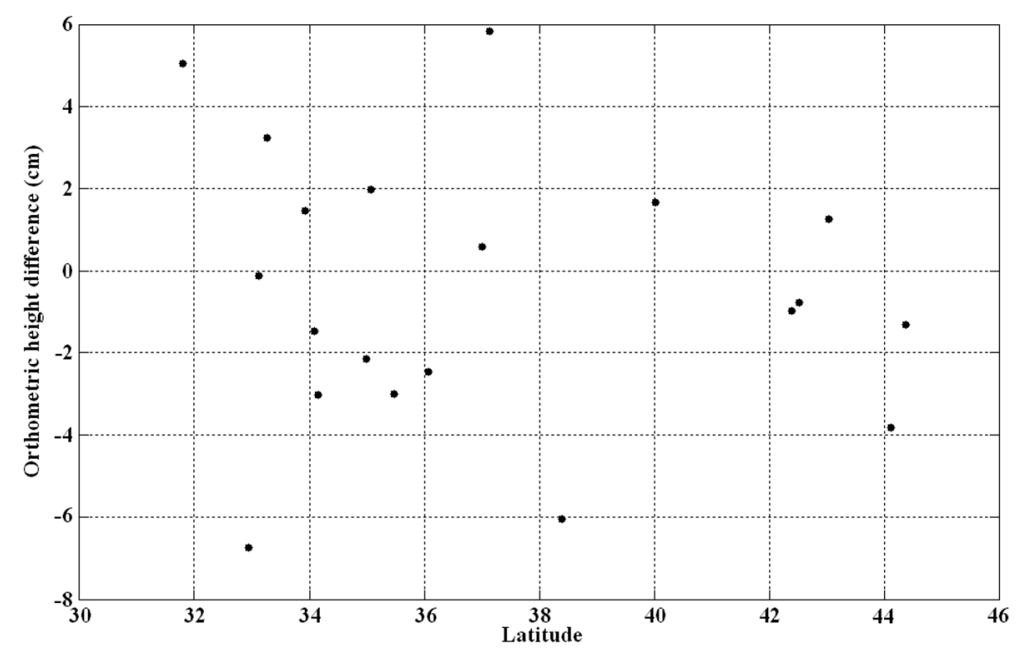

Fig. 6 Differences between established and converted orthometric heights at test points using offsets method

datum establishment, crustal deformations and related datasets among others. An understanding of this boundary would be a key to a realization of a geoid consistent vertical datum in Japan.

\section{Conclusions}

Recovery of orthometric heights from ellipsoidal heights using offsets method is found to perform better than planar fitting. In addition, this method does not constrain the gravimetric geoid model to fit onto the local vertical datum. The standard deviations of the differences between established and converted orthometric heights at randomly selected GPS/levelling test points over Japan are \pm 4 and $\pm 3 \mathrm{~cm}$ for planar fitting and offsets methods, respectively. The offsets method is therefore more appropriate for converting ellipsoidal heights to orthometric heights over Japan than planar fitting. It is expected that this accuracy would improve with improvements in geoid modelling and modernisation of local vertical datum.

\section{Competing interests}

The authors declare that they have no competing interests.

\section{Authors' contributions}

PAO and YF designed the research, and YF facilitated the data acquisition and interpretation. PAO carried out the computations and related analyses. He also wrote and revised the paper. Both authors read and approved the final manuscript.

\section{Acknowledgements}

We would like to thank the Geospatial Information Authority of Japan for providing GPS/levelling and other additional data sets covering the study area. We are also grateful to the anonymous reviewers for their valuable comments and suggestions that have improved the paper. A part of this study was conducted when the first author was a PhD. candidate at Kyoto University, Geodesy Laboratory.

\section{Author details}

'Department of Geomatic Engineering and Geospatial Information Systems, Jomo Kenyatta University of Agriculture and Technology, 62000-00200, Nairobi, Kenya. ${ }^{2}$ Graduate School of Science, Kyoto University, Kitashirakawa Oiwake-cho, Sakyo-ku, Kyoto 606-8502, Japan.

Received: 21 May 2015 Accepted: 11 August 2015

Published online: 21 August 2015

\section{References}

Amos MJ, Featherstone WE (2009) Unification of New Zealand's local vertical datums: iterative gravimetric quasigeoid computations. J Geod 83:57-68. doi:10.1007/s00190-008-0232-y

Ayhan ME (1993) Geoid determination in Turkey. Bulletin Géodésique 67(1):10-22. doi:10.1007/BF00807293

Cannon JB (1929) Adjustment of the precise level net of Canada 1928. Geodetic Survey of Canada Special Publication No. 28. Department of Energy, Mines and Resources, Ottawa, Canada

Doi H, Yahagi T, Shirai Y, Ohtaki M, Saito T, Minato T, Chiba H, Inoue T, Sumiya K, Sugawara J, Tanaka Y, Saita H, Kojima H, Yutsudo T, Amagai T, Iwata M (2005) The revision of geodetic coordinates of control points associated with the Tokachi-oki Earthquake in 2003. J Geospatial Inform Authority Japan 108:1-10

Forsberg R (1987) A new covariance model for inertial gravimetry and gradiometry. J Geophys Res 92(B2):1305-1310

Fukuda Y, Kuroda J, Takabatake Y, Itoh J, Murakami M (1997) Improvement of JGEOID93 by the geoidal heights derived from GPS/levelling survey. In: Gravity, geoid and marine geodesy, IAG Symposia, edited by Segawa J, Fujimoto H, Okubo S 117. Springer, Berlin Heidelberg New York, pp 589-596

Hiyama Y, Yamagiwa A, Kawahara T, Iwata M, Fukuzaki Y, Shouji Y, Sato Y, Yutsudo T, Sasaki T, Shigematsu H, Yamao H, Inukai T, Ohtaki M, Kokado K, Kurihara S, Kimura I, Tsutsumi T, Yahagi T, Furuya Y, Kageyama I, Kawamoto S, Yamaguchi K, Tsuji H, Matsumura S (2011) Revision of survey results of control points after the 2011 off the Pacific coast of Tohoku Earthquake. Bulletin Geospatial Information Authority Japan 59:31-42

Kearsley W (1977) Non-stationary estimation in gravity prediction problem. Report 256. Department of Geodetic Science and Surveying, Ohio State University, Columbus, USA

Knudsen P (1987) Estimation and modelling of the local empirical covariance function using gravity and satellite data. Bulletin Géodésique 61(2):145-160. doi:10.1007/BF02521264

Krarup T (1969) A Contribution to the mathematical foundation of physical geodesy. Report 44. Danish Geodetic Institute, Copenhagen

Krige DG (1951) A statistical approach to some basic mine valuation problems on the Witwatersrand. J Chem Metall Min Soc S Afr 52(6):119-139

Kuroishi Y (2009) Improved geoid determination for Japan from GRACE and a regional gravity field model. Earth Planets Space 61:807-813 
Kuroishi Y, Ando H, Fukuda Y (2002) A new hybrid geoid model for Japan, GSIGEO 2000. J Geod 76(8):428-436. doi:10.1007/s00190-002-0266-5

Miyahara B, Kodama T, Kuroishi Y (2014) Development of new hybrid geoid model for Japan, "GSIGEO2011". Bulletin Geospatial Information Authority Japan 62:11-20

Moritz H (1973) Least-squares collocation. Deutsche Geodätische Kommission, Reihe A. Heft 75, Munchen

Moritz H (1980) Advanced physical geodesy. Wichmann Verlag, Karlsruhe

Odera PA, Fukuda Y (2014) Improvement of the geoid model over Japan using integral formulae and combination of GGMs. Earth Planets Space 66:22. doi:10.1186/1880-5981-66-22

Odera PA, Fukuda Y (2015) Comparison of Helmert and rigorous orthometric heights over Japan. Earth Planets Space 67:27. doi:10.1186/s40623-015-0194-2

Odera PA, Fukuda Y, Kuroishi Y (2012) A high-resolution gravimetric geoid model for Japan from EGM2008 and local gravity data. Earth Planets Space 64(5):361-368. doi:10.5047/eps.2011.11.004

Pan M, Sjöberg LE (1998) Unification of vertical datums by GPS and gravimetric geoid models with application to Fennoscandia. J Geod 72(2):64-70. doi:10.1007/s001900050149

Pavlis NK, Holmes SA, Kenyon SC, Factor JK (2012) The development and evaluation of the Earth gravitational model 2008 (EGM2008). J Geophys Res 117, B04406. doi:10.1029/2011JB008916

Rapp RH, Balasubramania N (1992) A conceptual formulation of a world height system, Report 421, Department of Geodetic Science and Surveying. Ohio State University, Columbus, USA

Rizos C (1980) The role of the gravity field in sea surface topography studies. Report S 17, PhD thesis. School of Surveying, University of New South Wales, Sydney, Australia

Schaffrin B (1989) An alternative approach to robust collocation. Bulletin Géodésique 63(4):395-404. doi:10.1007/BF02519637

Schaffrin B (2001) Softly unbiased prediction part 2: the random effects model. Bollettino di Geodesia e Scienze Affini 60(1):49-62

Tobita M (2009) PatchJGD, software for correcting geodetic coordinates for coseismic displacements. Geodetic Society Japan 55(4):355-367

Tscherning CC (1976) Covariance expressions for second and lower order derivatives of the anomalous potential. Report 225, Department of Geodetic Science and Surveying. Ohio State University, Columbus, USA

Vaniček P, Krakiwsky EJ (1982) Geodesy: The concepts, 1st edn. North-Holland Publishing Company, Amsterdam

\section{Submit your manuscript to a SpringerOpen ${ }^{\circ}$ journal and benefit from:}

- Convenient online submission

- Rigorous peer review

- Immediate publication on acceptance

- Open access: articles freely available online

- High visibility within the field

- Retaining the copyright to your article

Submit your next manuscript at $\gg$ springeropen.com 